Reviews in Digital Humanities • Vol. 2, No. 5

\title{
Editors' Note: May 2021
}

Roopika Risam ${ }^{1}$, Jennifer Guiliano ${ }^{2}$

${ }^{1}$ Salem State University, ${ }^{2}$ IUPUI

Published on: May 10, 2021

DOI: $10.21428 / 3 e 88 f 64 f .96 a 31 d b 9$

License: Creative Commons Attribution 4.0 International License (CC-BY 4.0). 
Here at Reviews in Digital Humanities, we're excited to share the May 2021 issue of the journal, which brings together four projects nominated for review by digital humanities communities, our editorial board, and project directors.

In Reviews, we publish two types of issues: special issues and open issues. For the last several months, we have published special issues, which are proposed by guest editors. Guest editors select projects for review and provide names of potential reviewers while we handle solicitation requests, editing, and preparation of the issue. We have published special issues on borderlands digital humanities, Latinx digital humanities, and Jewish digital humanities, as well as issues based on a graduate class project. Upcoming special issues include Black digital humanities, sound studies, pedagogy, and the Digital Black Atlantic.

Open issues are put together from projects that come through our open call for submissions. Once we have received an overview, we identify reviewers and request a 30-day turnaround for the review. The pandemic has proven challenging to our goal of moving a project from submission to published review within 90 days. There are two primary areas where the workflow stalls. First, some of our reviewers, particularly those with caregiving responsibilities, need more time to complete their reviews. Being responsive to the needs of our communities at this time, we have regularly extended deadlines for reviews as needed. The other challenge has been finding reviewers who are able to spare the time with everything else on their plates. While many of our solicited reviewers have provided names of other colleagues we could approach, the cycle of snowballing through new reviewers slows down our workflow. We're working flexibly to negotiate these challenges with care and concern for our communities guiding our practices.

This month's open issue features projects that facilitate spatio-temporal analyses with digital methods:

- Mapping Marronage, created by Annette Joseph-Gabriel and reviewed by Shavange Scott;

- GeoNewsMiner, created by Lorella Viola and Jaap Verheul and reviewed by Avery Blankenship;

- Land and Legacy, created by Janet S. Dunkelbarger, Connor Kenaston, Natasha RothRowland, Lauren Van Nest, and Chloe Down Wells; and

- Visualizing Objects, Places, and Spaces, created by Beth Fischer and Hannah Jacobs and reviewed by Brandon Walsh. 
These projects speak to the range of approaches that geohumanities makes possible. Mapping Marronage demonstrates how a capacious definition of marronage combined with archival research and map-based approaches offer insight on connections between enslaved people in the circum-Atlantic world in the 18th and 19th centuries. Focused on the 1980s and beyond, Land and Legacy provides a digital intervention in critical university studies, examining how land acquisitions by the University of Virginia have affected local communities and serving as a powerful tool for advocacy. GeoNewsMiner provides users with a powerful tool for uncovering geographical dimensions of historical newspapers, while its use case, the Chroniclitaly 2.0 data set of Italian immigrant newspapers in the U.S., suggests how space and place can be used to understand ethnic identities. And Visualizing Objects, Places, and Spaces serves as an invaluable toolkit for project development, with an emphasis on visual studies, place, and space.

Reviews in Digital Humanities is committed to facilitating peer review for the wide range of digital humanities scholarship being developed. We welcome all methodological approaches and are particularly interested in digital scholarship in Black, Indigenous, Latinx, and Asian studies, as well as projects outside of the U.S. Join our experiment in peer review by submitting a project for review, proposing a special issue, nominating a project you admire, volunteering for our reviewer pool, and telling your colleagues and students about the journal.

Ideas? Questions? Thoughts? Concerns? Contact the editors, Jennifer Guiliano and Roopika Risam, at reviewsindigitalhumanities@gmail.com or through the Twitter hashtag \#ReviewsInDH. 